\title{
Tron Days: Horizontal Integration and Authentic Learning
}

\author{
Eugene Li, Chris Rennick, Carol Hulls, Mary Robinson \\ Michael Cooper-Stachowsky, Eline Boghaert, William Melek, Sanjeev Bedi \\ University of Waterloo \\ eugene.li@uwaterloo.ca, crennick@uwaterloo.ca, chulls@uwaterloo.ca, \\ mary.robinson@uwaterloo.ca,mstachowsky@uwaterloo.ca, eline.boghaert@uwaterloo.ca, \\ william.melek@uwaterloo.ca,sbedi@uwaterloo.ca
}

\begin{abstract}
First year Mechatronics students at the University of Waterloo consistently do not see the connection between their fundamental math and science courses with the practise of engineering. To address this issue, the first year instructors came together to launch a two day Hackathon style project for the students called Tron Days. Tron Days featured small warm up problems dealing with advanced concepts in each of the courses, and big problems that drew from all of the first year courses. The challenges only had communication marks associated with them and provided an opportunity for sustained engagement with the concepts. The metrics used to measure the event showed that it was successful at addressing the desired outcomes, but could be further enhanced to address more material.
\end{abstract}

Index Terms-horizontal learning, experiential learning, mechatronics, interdisciplinary, innovative learning

\section{INTRODUCTION}

Every year, students enter the University of Waterloo with great dreams of what it means to be an engineer. These students imagine applying all of their knowledge to solve challenging real world problems, and to make a difference in the world. However, for many students, they fail to see the interconnections between their fundamental math, science and programming courses, and fail to see how they connect with engineering and their own end goals [1].

The first year teaching team met and discussed the outcomes that they saw for their courses, first year engineering and the program as a whole. From these desired outcomes, the different activities existing in the term were evaluated and holes and redundancies were identified. One of the major problems identified were the students lack of understanding the importance of the first year courses, as well as not seeing the interconnection between their fundamental courses. Different options to address this were discussed, such as a combined mini project, assignments spanning multiple courses or instructors swapping lectures to talk about different topics. Ultimately, the combined mini-project resonated with the teaching team the most and addressed the greatest number of desired outcomes. This mini project would eventually morph into Tron Days.

To alleviate the identified problem, and to allow students to gain a feeling of what it means to be an engineer, the Mechanical and Mechatronics Engineering (MME) department came together with all seven of the course instructors that teach in the first term of Mechatronics Engineering to design a two day challenge for the 200 students known as Tron Days. In these two days, all classes were canceled and the students were faced with real world problems that drew on their knowledge of chemistry, calculus, linear algebra, programming, engineering graphics and design, their first year courses [8]. The challenges were broken into two main sections: small, warm-up problems, and big open-ended problems. The small problems, called movie myths, were challenging problems drawing from individual course content, and were based on scenarios from Hollywood movies. These acted as warm up problems, that helped foster intrinsic motivation towards problem solving [6]. Once groups had submissions to all five small movie myths, they could begin working on the big problems. These problems were based on real-world applications, and were designed to integrate knowledge from all five of the first year courses, thus achieving horizontal integration of course content [10]. The big problems provided authentic opportunities for evaluating student communication and teamwork outcomes; as most of the grades for the event were hosted by the Introduction to Mechatronics course (MTE 100), the assessments focused on communication, teamwork, and the engineering design cycle, rather than the finished designs. The challenges were evaluated based on award applications that the students self-nominated for, as well as presentations to their peers demonstrating one example of engineering design they completed during the event.

Tron Days was used as a means of integrating other experimental teaching methods into MTE100, including explicit teamwork training [3], and self-reflection via e-portfolios. Student feedback was collected using start and end of term surveys, as well as a course assignment where the students were instructed to provide constructive criticism about the event. Various metrics were used to measure the different outcomes from the two days of challenges, and showed an increase in student engagement, understanding of interconnection between the courses, and knowledge of the engineering profession in more than 50 percent of the students.

\subsection{Hackathons as a Teaching Tool}

Hackathons have been shown to be an effective tool for promoting innovation and creativity in different industry ap- 
Proc. 2017 Canadian Engineering Education Association (CEEA17) Conf.

plications [4]. They allow for an idea to be driven through its conception and design to implementation [5]; thus allowing the idea to be tested throughout the different stages of its life cycle in a rapid manner. The challenges and products created from these hackathons have traditionally been based in the field of computer science. Given their popularity in industry, many instructors in the field of computer science have made the natural connection, and realized that the hackathon structure allows for students to learn course concepts in a hands on manner [9]. These challenges create an active classroom environment, allowing the cultivation and growth of technical skills desired in industry [9].

Research shows that hackathons act as an effective informal learning platform, as they provide a fun and informal environment that attract students to engage with the material outside of their traditional formats [7]. The research shows that these gamified formats encourage the students to delve into the material, rather than be purely motivated by the marks associated with them [7].

Although much of the research has been done in the field of computer science, there have been examples of effective implementations of hackathons where physical tangibles have been produced [2]. In [2], the authors offered a Hackathon where participants were challenged to design, build and program internet of things (IoT) wearable devices to accomplish challenges. The aim of the Hackathon was to encourage interest in STEM fields, but the results showed a marked increase in engagement with the material amongst all of the participants, as well as success in designing and building physical artifacts [2].

Given the successes in other fields, we aim to apply this format in an engineering context, with less focus on the programming aspects of the challenges, and greater emphasis placed on engineering analysis and the design process.

\section{First Year in Mechatronics ENGINEERING}

Students entering first year Mechatronics Engineering at the University of Waterloo come from a diverse range of backgrounds, with varied skills and experiences. Although every student is directly sorted into their respective disciplines upon acceptance to the university, there are many common courses that students take in their first year. These common courses form a standardized background in fundamental math and science required for success in any engineering discipline. In addition to these common courses, students take courses that have been tailored to their unique disciplines. For the first term Mechatronics program, these courses come in the form of a first year Mechatronics concepts course (MTE 100) , and an introduction to programming courses (GENE 121). The overarching goal of the first term of studies is to ensure a standard basis of understanding in the students, and to provide an introduction to the world of engineering and what it means to be an engineer.

To facilitate these goals, a major focus in the first year concepts course is professional practise and the practise of engineering. As every student in the Mechatronics program is enrolled in co-op, these points are given more weight and context with their relationship to co-op positions and working in industry. With half of the students looking for co-op positions beginning the next semester, specific lectures are allocated to co-op fundamentals, resumes and interviews. In these sessions there is a consistent focus on professionalism and presentation. This is reinforced with many communications milestones and deliverables tied to the marks associated for the first year concepts course.

\subsection{Overview of Courses}

The first term of Mechatronics engineering consists of five courses, broken up into several components within each course. The common courses in math and chemistry are coordinated amongst all engineering disciplines and share a common midterm and final, regardless of discipline. This leaves the first year concepts course and programming course to be uniquely tailored for the Mechatronics program.

The five courses that students take in their first term are:

- MTE 100 - Introduction to Mechatronics Engineering: This is the first year concepts course where students learn the fundamentals of Engineering, Engineering Design and Engineering Graphics.

- CHE 102- Chemistry for Engineers: Common Course that teaches core principles of chemistry applicable to engineering.

- MATH 115 - Linear Algebra for Engineering: Common course that teaches the fundamentals of linear algebra. This includes topics such as solving systems of equations, matrix operations, vector spaces and eigenvalues.

- MATH 116 - Calculus 1 for Engineering: Common course that provides the background and foundations for calculus. This includes topics such as trigonometry, inequalities, derivatives and integration.

- GENE 121 - Digital computation: Unique course offered only to the Mechatronics class in the fall term. The course provides an introduction to computer logic and programming. Students learn the fundamentals of computer programming in $\mathrm{C}++$ and RobotC and implement a final project with Lego NXT/EV3 in RobotC.

There are two cohorts of Mechatronics students enrolled in first year of the fall term. Each of the common courses is coordinated by a course coordinator for each section being taught. GENE 121 is taught by one instructor for both cohorts and MTE 100 is co-taught between three instructors. Although each section has its own instructor, as the midterm and final exams are common there are certain topics that must be taught by certain points in the term.

\section{ACTIVITY DESCRIPTION}

The Tron Days event was designed as a method to address several concerns and issues that instructors had seen within the Mechatronics program and first year engineering. The activity was advertised to the students from the beginning of the term as a large challenge, similar to a hackathon. The intent was to foster innovation with the internal hackathon concept [4]. 
Through their regular course work, the students self selected themselves into teams and established a team contract. The team contract served as a mechanism to address specific teamwork concepts [3], while allowing the groups to begin to form their own identity. The team contracts also provided a dry run for the students before their final term projects. The team contracts also served a method to explicitly outlined the team's work ethics, accountability and consequences for team members failing to meet the expectations.

Leading up to the event, the course instructors held bridge in activities that emphasized key concepts in their respective courses that would be pertinent to the Tron Days activity. This build up towards the event was further emphasized by the event kick off which was topped with an opening speech from the Dean of Engineering. The build up of the event showed its importance to the instructors and teaching staff, which echoed with the students.

The Tron Days activity itself was divided into small problems that were completed first before big problems were released. These small and big problems, or challenges, spanned the first and second day of the Tron Days event. Near the end of the second day and final day, the groups were encouraged to self nominate themselves for award applications. The award applications required the groups to submit evidence for what they believed to be exceptional pieces of work. As the award applications were being reviewed by the judges, the groups made quick presentations to their course teaching assistants. These presentations replaced previous presentations that were held on a technical topic, and had been re-purposed for a technical discussion of their work for Tron Days. Once the presentations were completed, the groups gathered together for an awards ceremony to cap off the event.

\section{1. "Small" Challenges}

The "small" challenges were designed as a series of warm up problems with the goal of introducing the teams to the concept of working together and to investigate and seek out knowledge on their own [2].

Each of the problems touched on key concepts that the students learned in their courses, but with scope larger than anything that they had seen. These problem extensions forced the students to think about the concepts that they had learned in class and apply them in new ways beyond what they had been shown.

Each of the small problems were focused on one individual course and were centered around movie myths. For example, the chemistry problem evaluated the feasibility of the experiments done in the movie "The Martian". By associating the problems with different movies, the students were given a "Mythbusters" type framework, introducing a sense of novelty to the problems, but also giving more context for them. These problems were purposefully designed beyond the level of knowledge of the individual students. The goal of this approach was to encourage students to work together, and to explore and look for different solutions, while practising their course material.

\section{2. "Big" Challenges}

Once the small challenges were completed, the groups gained access to the big challenges. These big problems formed the majority of the time spent on the event and acted as a medium for groups to tackle problems of larger scope for a sustained period of time. The big challenges were designed to draw from content from each of the courses that the students took within their first term. The challenges could only be successfully completed by using the knowledge from each course to solve the problems at hand. These problems were common upper year engineering problems, which used the fundamental concepts that the first year students had learned, but applied within a more sophisticated context. Given that the problems were well beyond the ability of a standard first year student, they were posed as sustained challenges for the groups to tackle. By structuring the problems in this manner, the groups were provided with a scaffolding for how to approach the bigger problems.

Furthermore, in an effort to encourage discovery and experimentation, there were no marks associated with the success of the challenges. Instead of marks for the challenges, students were given opportunities to self nominate their groups for various awards. These awards were tied to physical rewards and provided an aura of prestige. Success in the big problems provided groups with more material and evidence for their award nominations. There were awards associated for each of the courses and focused primarily on demonstration of skills that the students had gained. For many first year students developing their resumes, there exists an unusual focus on projects completed, rather than skills gained. In an attempt to repair this disconnect, emphasis on skills gained throughout the event was given for the awards.

The only deliverables that the groups had to produce during the two days of the event, were presentations on their work and the award submissions themselves. These deliverables went towards to the professionalism and communication deliverables in the concepts course MTE 100, which replaced previously existing written and oral communication deliverables. In addition, other course deliverables, such as team contracts, eportfolios, etc., were tied together with the Tron Days event. This prevented additional work from being added and acted as an opportunity for the students to review and practise course material for their other courses.

By focusing exclusively on communications deliverables the students were able to follow the engineering design process in a more risk free environment. This encouraged them to iterate on designs, rather than attempt to rush a product to completion. By shifting this focus, we believe that the students were able to more actively engage in the material and investigate it deeper. Furthermore, given the naturally competitive nature of the students, the award applications provided a reasonable incentive for the majority of the groups to perform well.

\subsection{Outcomes and Metrics}

The key outcomes that we hoped to achieve from the event were an increase in understanding the relevance and 
Proc. 2017 Canadian Engineering Education Association (CEEA17) Conf.

TABLE I: Outcomes and Metrics

\begin{tabular}{|l|l|}
\hline Outcome & Metric \\
\hline Teamwork & $\begin{array}{l}\text { Team Formation Activity Data, } \\
\text { End of Term Survey, Team Con- } \\
\text { tracts }\end{array}$ \\
\hline Feeling like an Engineer & End of Term Survey data \\
\hline Problem Solving Ability & $\begin{array}{l}\text { Big Problem results and Award ap- } \\
\text { plication submissions }\end{array}$ \\
\hline Horizontal Integration & End of Term survey data \\
\hline Practise of Course Material & $\begin{array}{l}\text { Small problem results and Award } \\
\text { application submissions }\end{array}$ \\
\hline Communication Ability & $\begin{array}{l}\text { Presentation marks, Award appli- } \\
\text { cation, E-portfolio, Post TronDays } \\
\text { Feedback assignment }\end{array}$ \\
\hline $\begin{array}{l}\text { Professional Skill Develop- } \\
\text { ment }\end{array}$ & $\begin{array}{l}\text { Resume Review, Discussion of Ap- } \\
\text { proximations made, Time manage- } \\
\text { ment during Tron Days, Resiliency } \\
\text { demonstrated }\end{array}$ \\
\hline
\end{tabular}

interconnection of the first year courses, professionalism and understanding of the engineering profession as well as development of soft skills. Given the varied outcomes, a series of measurement metrics were used to evaluate the outcomes. These were a combination of surveys, written reflections and comparisons between deliverables from previous years and the current group.

We evaluated the student response to the activity using a variety of measurement approaches, selected to most accurately capture each outcome. These outcomes and metrics have been summarized in Table I.

Many of the metrics used existed in the past as previous assignments and milestones. For example, students have always prepared resumes and received feedback on them. These pre-existing deliverables allowed for a consistent measure of the impact of the activity against previous years. In addition, measures such as the problem results could be easily compared to the performance that previous years have had against relatively comparable problems.

This left the end of term survey results, which specifically addressed the Tron Days activities. The end of term survey is a large survey that provides many measures for different topics. In the survey were questions that specifically targeted many of the outcomes and provided a measure of the student perception to the outcomes and the interventions.

\section{Results AND Discussion}

The Tron Days activity aimed to address many concerns the instructors were seeing in the first year of Mechatronics engineering and their impacts on the students as they progressed through their degrees.

The measures we placed showed an overwhelmingly positive impact for teamwork skills. As seen in Fig.1, the vast majority of the students indicated that Tron Days was an effective method for them to practise their teamwork skills. These skills were re-enforced later on in the term when the students tackled their major course projects. Early analysis of the data shows that many of the groups worked more effectively together in the final projects in comparison to previous years.

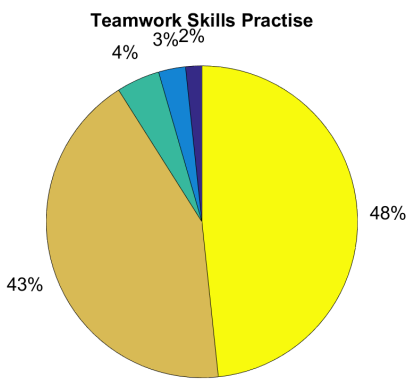

Stongly Disagree $\square$ Disagree $\square$ Neutral $\square$ Agree $\square$ Strongly Agree

Fig. 1: Practising Teamwork Skills

One of the more abstract outcomes that we had hoped to measure was the feeling of an engineer. As one can imagine, measuring a feeling can be a very subjective process. The goal of this outcome was for the students to have an enhanced understanding of the practise of engineering, as well as the engineering design cycle. In the majority of problems that first year students are faced with, the depth of the problem is relatively shallow to keep the key concepts in focus. The Tron Days problems forced the students to engage with the material for a longer duration, allowing for actual iteration of the design process. However, the data in Fig.2 and the results from the feedback assignment indicate a somewhat mixed feeling from the students. Many of the students felt that the problems were overly analytical in nature, and that to be a true engineer, they must physically build their designs themselves.

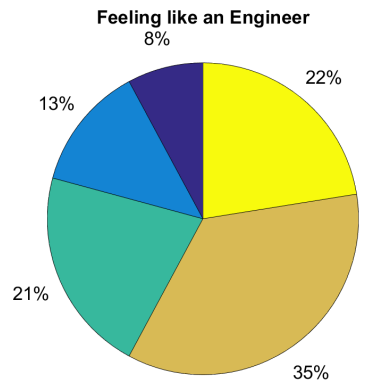

$\square$ Stongly Disagree $\square$ Disagree $\square$ Neutral $\square$ Agree $\square$ Strongly Agree

Fig. 2: Feeling Like an Engineer

One of the major outcomes of Tron Days was for the students to understand the interconnections between their courses, why they were taking them and how they related to their careers in engineering. The goal was for the courses to be seen in the context of engineering as a whole, and to hopefully motivate the students to be more invested in the material.

The main vehicle for this outcome was the big problems. The problems were structured in such a way that for the groups 
Proc. 2017 Canadian Engineering Education Association (CEEA17) Conf.

to truly be successful they would require knowledge from multiple courses to solve the challenges. Although this is a somewhat arduous task in the context of defined problems, it becomes relatively straightforward when the problem is more open ended. This stems from the fact that the open ended problems often have different solutions, that can be approached from different ways. This point was reinforced with the end of term survey results in Fig. 3 that showed a large number of the students saw this point.

Although the relevance of the courses did not have a large impact on the course marks, the perspective that the students had about the courses improved, with the majority of them understanding why the courses exist in the Mechatronics program and are taken in their first term. This is emphasized in Fig.4 and Fig. 5.

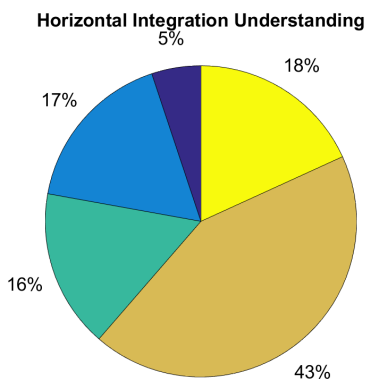

Stongly Disagree $\square$ Disagree $\square$ Neutral $\square$ Agree $\square$ Strongly Agree

Fig. 3: Horizontal Integration

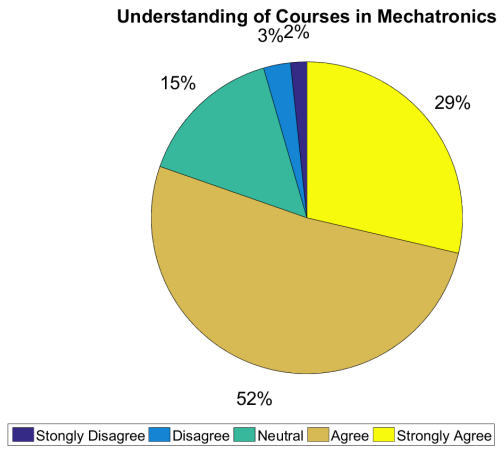

Fig. 4: Understanding of Courses

A desired outcome from Tron Days was to increase the problem solving ability of the students. By exposing the students to problems beyond their typical ability, they were forced to think beyond the concepts that they had learned in class and to approach the problems from a different way [7]. Although this approach is typically desirable, given the grade focused nature of many of the students, the temptation to obtain a solution rather than think it through is typically prevalent. By disassociating the problems with any marks, the students could delve into the problems without fear. This

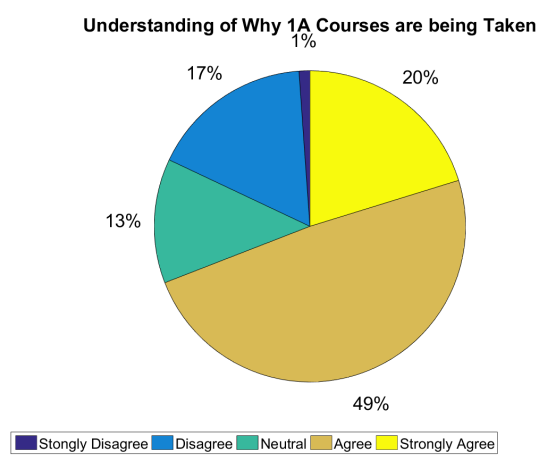

Fig. 5: Understanding of Why Courses are Taken

appeared to have a positive impact on the problem solving ability of the students when they returned to their "standard" problems. This is reinforced by the preception of the student's ability, seen in Fig.6.

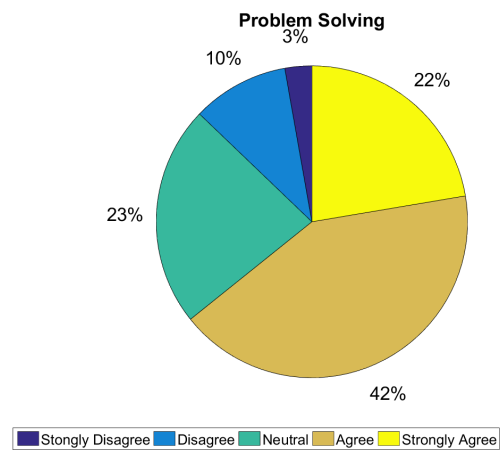

Fig. 6: Positive Impact on Problem Solving

The course instructors and teaching staff hoped that Tron Days would be an effective means for the students to engage with the course material. To facilitate the event, the classes for the two days of Tron Days were rescheduled. Many feared that this would result in loss of content in their courses, however it turned out that the opposite of this was true. The students remarked in their feedback assignments and end of term surveys that Tron Days was an effective method for practising the course material. As shown in Fig. 7, over fifty percent of the class agreed that it was an effective means for practising the content. Moreover, many students commented that they felt they received more contact time with the teaching team through Tron Days, and established a better relationship with their instructors.

Although there were many metrics set in place for communication and professionalism the impact Tron Days had on these outcomes is still unclear. The deliverables associated with these outcomes did not show large deviations from previous years, but may have interesting implications on this cohort of students in future years. It will be of interest to study this group as they progress through their degrees to see if Tron 
Proc. 2017 Canadian Engineering Education Association (CEEA17) Conf.

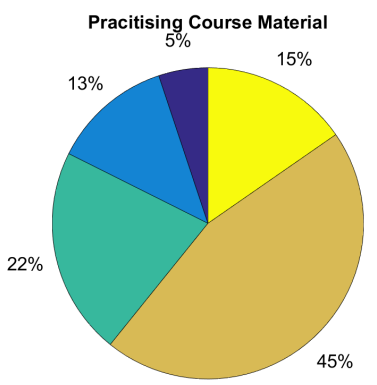

Stongly Disagree $\square$ Disagree $\square$ Neutral $\square$ Agree $\square$ Strongly Agree

Fig. 7: Practising Course Material

Days had a positive effect on these attributes.

From the outcomes we had aimed to achieve and the metrics we used to measure them the Tron Days activity was a success. However, in analyzing the feedback data a strong trend emerged. The activities were seen as overly analytical by the students and lacked hands on skills that they deeply desired. For the students, the hunt for the first co-op position is ever present. The students are constantly aiming to develop more hands on skills to add to their resumes to provide an edge in the search for work. This is echoed by the employers statements, indicating that an increase in hands on skills in students is desirable. Nevertheless, the majority of the students felt that Tron Days was a valuable experience for them, and that they gained skills that were of use. This is outlined in Fig. 8.

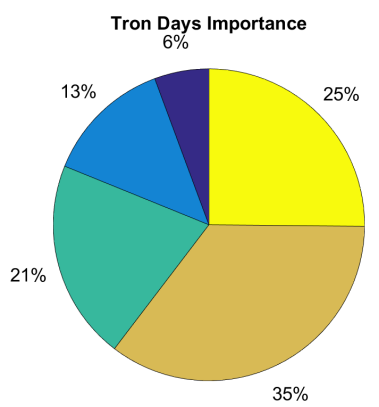

Very Unimportant $\square$ Unimportant $\square$ Neutral $\square$ Important $\square$ Very Important

Fig. 8: Recognizing the Importance of TronDays

\section{Conclusion And NeXt Steps}

First year Mechatronics students at the University of Waterloo come in with a great deal of skills and knowledge obtained throughout their high school curriculum. However skillful the students may be, there exists a large disconnect between what the students value in their coursework and how it relates to the professional practise of engineering.To address issues, such as seeing the value and need of their fundamental math and science courses, as well as soft skills such as teamwork and communication, the Tron Days event was held.

The event was a Hackathon style challenge where students were given problems to be completed in teams. These problems were larger in scope than any that the students had seen to date, and drew from the concepts they had learned in all of their classes, as well as extensions based on more advanced engineering concepts.

The emphasis of the event was directed towards teamwork and communication, as the only marked deliverables were for these categories. This encouraged the groups to take risks and participate more fully in the engineering design cycle.

The surveys and metrics used showed that the majority of the students gained a considerably deeper understanding of why they were taking the courses that they were taking in their first term, as well as their relation to the practise of engineering. In addition, the picture of what it meant to be an engineer became clearer to many of the students. These notions were re-iterated in other deliverables and discussions that were held later in the semester. Furthermore, Tron Days was an effective way for the students to practise the course material in their other courses, and draw deeper connections to advanced topics.

Although Tron Days was an effective tool for addressing the identified outcomes, a major area for improvement is the implementation of hands on skills. The Tron Days problems were largely focused on the analytical aspects of the design process and left little room for implementation of physical designs.

\section{ACKNOWLEDGMENT}

The authors would like to thank the IDEAS Clinic and course instructors for their support in the development and implementation of the TronDays event.

\section{REFERENCES}

[1] Design of an Introductory Engineering Design and Communication Course Which Integrates First Semester Courses.

[2] J. R. Byrne, K. OSullivan, and K. Sullivan. An iot and wearable technology hackathon for promoting careers in computer science. IEEE Transactions on Education, 60(1):50-58, Feb 2017.

[3] Jobidon E. Prier A. Khaniyev T. Rennick C. Al-Hammoud R. Hulls C. Grove J. A. Mohamed S. Johnson S. J. Bedi S. Hurst, A. Towards a multidisciplinary teamwork training series for undergraduate engineering students: Development and assessment of two first-year workshops.

[4] M. Komssi, D. Pichlis, M. Raatikainen, K. Kindstrm, and J. Jrvinen. What are hackathons for? IEEE Software, 32(5):60-67, Sept 2015.

[5] M. Komssi, D. Pichlis, M. Raatikainen, K. Kindstrm, and J. Jrvinen. What are hackathons for? IEEE Software, 32(5):60-67, Sept 2015.

[6] John Lawlor, Kevin Marshall, and Brendan Tangney. Bridge21 exploring the potential to foster intrinsic student motivation through a teambased, technology-mediated learning model. Technology, Pedagogy and Education, 25(2):187-206, 2016.

[7] Arnab Nandi and Meris Mandernach. Hackathons as an informal learning platform. In Proceedings of the 47th ACM Technical Symposium on Computing Science Education, SIGCSE '16, pages 346-351, New York, NY, USA, 2016. ACM

[8] University of Waterloo. Mechatronics program overview.

[9] Michael Skirpan and Tom Yeh. Beyond the flipped classroom: Learning by doing through challenges and hack-a-thons. In Proceedings of the 46th ACM Technical Symposium on Computer Science Education, SIGCSE '15, pages 212-217, New York, NY, USA, 2015. ACM. 
Proc. 2017 Canadian Engineering Education Association (CEEA17) Conf.

[10] W. D. Snyman and J. Kroon. Vertical and horizontal integration of knowledge and skills a working model. European Journal of Dental Education, 9(1):26-31, 2005. 